\title{
Topic Selection of Course Project for Principle of Machinery with Reference to Curriculum Setting of Mechanical Engineering in British Universities
}

\author{
Ying Zhou1 ${ }^{*}$, Xiaozhou Hu' ${ }^{1}$, Zhilian Zheng1, Jiezhen Liu' ${ }^{1}$, Rulin Shen ${ }^{1}$, Shengfeng Qin² \\ ${ }^{1}$ School of Mechanical and Electrical Engineering, Central South University, Changsha, China \\ ${ }^{2}$ School of Design, Northumbria University, Newcastle upon Tyne, UK \\ Email: *zhouying@csu.edu.cn
}

How to cite this paper: Zhou, Y., Hu, X.Z., Zheng, Z.L., Liu, J.Z., Shen, R.L. and Qin, S.F. (2019) Topic Selection of Course Project for Principle of Machinery with Reference to Curriculum Setting of Mechanical Engineering in British Universities. Open Journal of Social Sciences, 7, 499-505.

https://doi.org/10.4236/jss.2019.73041

Received: March 12, 2019

Accepted: March 26, 2019

Published: March 29, 2019

\begin{abstract}
Comparing structures of the mechanical engineering courses among three top British universities, the characteristics of their structure is analyzed. Based on the features of Chinese mechanical disciplines, enlightenment from Britain will be applied to course project for principle of machinery, with focus on topic selection and guidance, which will be more efficient than before to develop the students' ability and quality. Also the feasibility and development trend of the topic selection are mentioned.
\end{abstract}

\section{Keywords}

Mechanical Engineering, Curriculum Setting, Principle of Machinery, Course Project, Topic Selection

\section{Introduction}

According to The Complete University Guide [1], University Subject Tables 2018 of Mechanical Engineering, Cambridge University, Oxford University and Imperial College London are the top three universities of UK, while in 2019 [1], the order of top three changes as Cambridge University, Imperial College London and Oxford University. But anyhow, these three are good role models of universities of UK, even over the world. The experience of their education is worth learning by other universities.

Curriculum settings of Mechanical Engineering of Cambridge University, Oxford University and Imperial College London are chosen to be samples of this 
research. A detailed analysis and study of the curriculum setting of these three top-level British universities will be conducive to the improvement of the course project, the most practical link of principle of machinery in a Chinese university-Central South University. General characteristics of British mechanical disciplines, such as name of the subject specialty, training skill, cooperation with industry, course outline, featured course and assessment type, etc. are set to compare comprehensively the characteristics of mechanical engineering undergraduate or master majors in Cambridge University [2], Oxford University [3] and Imperial College London [4]. For simplicity, "Cambridge", "Oxford", "Imperial" will represent for these three universities as below.

\section{Comparison of Curriculum Settings in Mechanical Engineering}

\subsection{Name of Department/Educational Objectives/Name of Major}

Cambridge: Department of Engineering/to develop engineering knowledge, skills, imagination and experience to the highest levels in readiness for future career/The Cambridge Engineering course, three years with the BA (Honours) degree, or completion of the fourth year leads to the BA and MEng degrees [2].

Oxford: The Department of Engineering Science at Oxford/application of creative reasoning, science, mathematics (and of course experience and common sense) to real problems, unified course, integrates study of the subject across the traditional boundaries of engineering disciplines, topics in apparently diverse fields of engineering with well-structured fundamental understanding/The Engineering Science programme, four-year course, the degree of Master of Engineering [3].

Imperial: Mechanical Engineering Department/to turn the brightest, most ambitious students into twenty-first century engineers, and develop knowledge, skills, imagination and creativity/Mechanical Engineering, four-year course, the degree of Master of Engineering [4].

\subsection{Training Skills}

Cambridge: Open options, analytical, design and computing skills that underpin modern engineering practice [2].

Oxford: Application of creative reasoning, science, mathematics (and of course experience and common sense) to real problems. A unified course in Engineering Science, integrates study of the subject across the traditional boundaries of engineering disciplines with well-structured fundamental understanding [3].

Imperial: Courses will develop your knowledge, skills, imagination, creativity, intellectual agility, and the ability to work in multidisciplinary teams [4].

\subsection{Cooperation with Industries}

Cambridge: Engineers with enough broad education and training increasingly 
manage industries. Manufacturing engineers with particular expertise in the design and operation of manufacturing facilities become leaders of multidisciplinary teams more often.

All-life cycle or multi-life cycle of product: a thorough grounding in manufacturing technology and management, together with an understanding of the full range of activities involved from market analysis through product design and production, to sales and distribution, all set firmly within a financial and business context. Beside the engineering and business sides, a sound understanding of the human aspects of industry and develop leadership and people skills are also acquired [2].

Oxford: Undergraduates are strongly encouraged to obtain Industrial experience, which is an extremely important adjunct to an academic engineering education. One way to get it is by being sponsored, other ways are generally available through your careers teacher, or from the engineering institutions [3].

Imperial: Work continuously with industry to ensure that our courses-and the facilities, and equipment learning to use-remain relevant to the profession. Undergraduates will benefit from access to facilities and equipment that match those used in industry (including Instron machines for testing the strength of engineering materials, and microcontroller kits for testing the performance of mechatronic systems) [4].

\subsection{Course Outline}

Cambridge: Teaching is provided through a mixture of lectures, practices, projects and supervisions. Part I (Years 1 and 2) provides a broad education in engineering fundamentals, enabling students to make a genuinely informed choice about the area in which to specialise from their third year (many students change direction as a result). Part II (Years 3 and 4) then provides in-depth training in their chosen professional discipline [2].

Oxford: The first two years are devoted to topics that all Engineering undergraduates are required to study. In the third and fourth years there is scope for specialization into one of six branches of engineering: Biomedical, Chemical, Civil, Electrical, Information and Mechanical. Decisions about which of these will be their specialization can be deferred until the third year. In the fourth year there may be opportunities to study abroad [3].

Imperial: Teaching in lectures, by problem sheets, in tutorials, through workshop training and laboratory work, with group practical exercises, a literature research project, a group design project and research project. First two core years of intensive engineering science. Years three and four mostly comprise elective study and project work. The elective technical modules cover some of key research areas such as tribology and combustion, as well as solid mechanics, thermofluids, robotics and nuclear energy. The non-technical modules can be as diverse as design, art and creativity, or business economics (delivered online by Imperial College Business School). The last two years of the course involve substantial group and individual project work, with freedom to choose topics pro- 
posed by staff based on their cutting edge research or even "pitch your own" ideas [4].

\subsection{Featured Course}

\section{Cambridge: Manufacturing Engineering (Part II course)}

Manufacturing Engineering is offered as a Part II-only course. Students at any College can apply to transfer to Manufacturing Engineering after completing Part I of Chemical Engineering or Engineering. Applications from other science courses may be considered [2].

\section{Oxford: Designation of chartered engineer}

The course is accredited every four years by the major engineering institutions in respect of the initial requirements for the designation of chartered engineer [3].

\section{Imperial: Imperial Horizons}

An elective module of Imperial Horizons, which offers a wide range of short courses-including languages, humanities and business skills-designed to broaden students education, inspire their creativity and enhance their professional impact [4].

\subsection{Assessment Types}

Cambridge: Being assessed each year through coursework and written exams [2].

Oxford: Year 1: First University examinations: Four written papers; Assessment of Engineering practical work.

Year 2: Final University examinations, Part A: Four written papers; Assessment of Engineering practical work.

Year 3: Final University examinations, Part B: Six written papers; Assessment of Engineering practical work; Project reports (Engineering Computation and Design Project).

Year 4: Final University examinations, Part C: Six written papers; Project report [3].

Imperial: Assessment methods are written examinations, practical, and coursework assignments [4].

\section{Generalization}

Cambridge University, Oxford University and Imperial College London have their own distinguishing features in education [2] [3] [4]. They are generalized as below:

1) All of the three universities engage continuously with industry to ensure their courses remaining relevant to the profession.

2) Course project plays an important role in engineering teaching and experiencing while learning knowledge will enhance efficiency of teaching and learning. 
3) Not only knowledge, but also skills, such as imagination, creative reasoning, creativity, intellectual agility, and the ability to work in multidisciplinary teams are all emphasized.

4) Well-structured fundamental understanding of multidisciplinary, study of the subject across the traditional boundaries of engineering disciplines can be exploited to give efficient teaching.

In a word, their universities are more like a practice ground, where undergraduates are trained with comprehensive abilities, even languages, humanities and business skills, more than professional engineering. Then graduates will acclimatize themselves to the role of industry market smoothly.

\section{Discussion}

\subsection{Current Situation of Course Project for Principle of Machinery}

Course project for principle of machinery is an important practical link in mechanical principle course, which plays a very important role in the practical design of a relatively independent, in cultivating students' ability in mechanical design (focus on the design of motion scheme of mechanical system) and the innovation consciousness and ability.

The traditional topics of course project of principle of machinery are shaping machine and so on. Though the six-bar linkage of shaping machine is a proper topic to course project for its difficulty level, but over twenty years, this topic has been dominating in training of course project. As materials about six-bar linkage of shaping machine are everywhere on the net, better students might study their own data while learning the existing sample, ordinary ones put their data into samples and draw their own, but those not such good might just copy them. Renovation for course project has being called for years, authors have tried some methods such as optimization to improve, but efficiency doesn't grow much. The main reason will be the limitation of topics. So teachers need to widen topics by reference to other universities [5] [6] [7].

\subsection{Inspiration by Contrast}

By studying British top three universities' curriculum setting, project training usually begins since year three, and lasts till graduating. For British universities collaborating closely with industries, there are plenty of real multidiscipline problems coming from industries to choose for projects.

Though to a 2 -week project of one simple course, course project for principle of machinery might not jump to the level of those multidiscipline projects, but it could train the ability of consulting reference and problem-solving skills of students by proper guiding and teamwork.

\subsection{How to Improve Project Design}

As guide of students, teachers should dig new topics and good ideas of course project all the time, where continuously learning is also necessary to teachers. 
New or updated topics should be with new ideas and requirements, enable students to complete it in a limited time, and moderately expand their abilities and interests.

Each topic would better be able to bring new thinking and improvement, which can ensure teaching demands of professional theoretical knowledge and ability training, such as inquiring literature, extracting useful information, independently solve practical problems, coordinating of teamwork, and assigning team members reasonably.

More project topics will come from industry, and serve for real problems, first from simple ones, then to help complex one.

\section{Conclusion}

With reference to the establishment of mechanical engineering discipline in Britain, according to the different teaching methods in China and Britain, the training of students' different abilities should be focused on, so as to serve the market better and adapt to the development of the society. The inspiration can be used to improve the setting and structure of principle of machinery's course project in our university, which will be beneficial to the improvement of teaching and the effectiveness of the project design.

\section{Acknowledgements}

This work is partially supported by the program of China Scholarships Council (Grant No. 201706375019), Natural Science Foundation of Hunan Province (Grant No. 2017JJ3326), Key Laboratory of Safety Design and Reliability Technology for Engineering Vehicle, College of Hunan Province (Grant No. 2016 KF1603), National Postdoctoral Program for Innovative Talents (No. BX201600193), Postdoctoral Science Foundation (No. 2017M612579), Scientific Research Fund of Hunan Province Education Department (No. 17B009), the scholarship under the State Scholarship Fund managed by the China Scholarship Council (No. 201706375019), and fully supported by 2017 Central South University Education and Teaching Reform Research Project under Grant 10100-160010014.

\section{Conflicts of Interest}

The authors declare no conflicts of interest regarding the publication of this paper.

\section{References}

[1] Complete University Guide Team (2019) University Subject Tables 2019. https://www.thecompleteuniversityguide.co.uk/league-tables/rankings?s=Mechanic al+Engineering

[2] Cambridge Admissions Office (2019) Engineering at Cambridge. https://www.undergraduate.study.cam.ac.uk/courses/engineering

[3] Oxford's Main Public Facing Website (OxWeb) (2019) Engineering Science. https://www.ox.ac.uk/admissions/undergraduate/courses-listing/engineering-scienc $\mathrm{e}$ ?wssl=1 
[4] Imperial College London Website (2019) Department of Mechanical Engineering. http://www.imperial.ac.uk/study/ug/courses/mechanical-engineering-department/

[5] Zhu, N. (2018) Effectiveness of Involving the Industrial and Business Professions into Mechanical Engineering Capstone Course. International Journal of Mechanical Engineering Education, 46, 31-40. https://doi.org/10.1177/0306419017718920

[6] Kanelopoulos, J., Papanikolaou, K.A. and Zalimidis, P. (2017) Flipping the Classroom to Increase Students' Engagement and Interaction in a Mechanical Engineering Course on Machine Design. International Journal of Engineering Pedagogy (iJEP), 7, 19-34. https://doi.org/10.3991/ijep.v7i4.7427

[7] Cheng W.M., Wu, X., Zhang, Z.Q., Liu, F., Zhang, M. and Guo, P. (2013) Effective Project-Oriented Approach for Training Professional Mechanical Engineers in Undergraduate Education. International Journal of Mechanical Engineering Education, 41, 289-296. https://doi.org/10.7227/IJMEE.41.4.3 